\section{Investigation of the} patient with pleural effusion

NM Rahman BM BCh MA MRCP, MRC Training Fellow and Specialist Registrar, Oxford University, Oxford Centre for Respiratory Medicine, Churchill Hospital, Oxford

M Munavvar MD DNB FRCP, Consultant Chest Physician, Lancashire Teaching Hospital NHS Foundation Trust, Preston

\section{Clin Med 2009;9:174-8}

Pleural effusion is a common clinical problem and may present to a wide range of specialties. Accurate aetiological diagnosis is key to subsequent management, requiring a multidisciplinary approach and knowledge of the correct investigation pathway. This article will focus on appropriate staged investigations for the patient presenting with pleural effusion rather than on its causes or treatment.

\section{Clinical syndromes}

Pleural effusion is often detected on plain chest radiography as an incidental finding and patients may be asympto- matic. Clinical symptoms are variable, depending on the size and aetiology of the effusion and rarely specific enough to suggest a diagnosis in the absence of further investigations. Large effusions are likely to be associated with dyspnoea, but this is often a late finding and oxygen saturations may not be severely lowered. Dyspnoea is the result of impaired mechanics and increased intrapleural pressure swings.

The presence of chest pain implies involvement of the parietal pleura which is heavily innervated. Inflammation, infection and malignant involvement may produce pain, including shoulder tip symptoms associated with diaphragmatic involvement. Weight loss, anorexia and malaise may imply malignancy or infection (eg empyema).

\section{Causes}

Pleural effusions are divided into transudative and exudative (Table 1). They are diagnosed according to pleural fluid biochemical characteristics (see below). However, transudates occur with structurally normal pleura, in which oncotic or hydrostatic pressure results in fluid leak. In contrast, exudates occur with damaged or altered pleura, resulting in loss of tissue fluid and protein causing fluid formation.

Table 1. Causes of exudative and transudative effusions and biochemical parameters. Transudates Exudates

Biochemical definition

Protein $<30 \mathrm{~g} / \mathrm{I}^{*}$

Protein $>30 \mathrm{~g} / /^{*}$

Causes
Left ventricular failure

Renal failure

Liver failure

Low protein states

\author{
Infection (empyema/parapneumonic effusion/TB) \\ Malignancy (primary and secondary) \\ Inflammation (vasculitis, autoimmiune disease) \\ Pulmonary embolus (with infarction) \\ Oesophageal perforation \\ Hypothyroidism \\ Chylothorax/pseudochylothorax \\ Post-cardiac surgery \\ Drugs
}

Light's criteria

An exudate is diagnosed if one or more of the following criteria are met:

- pleural fluid protein/serum protein $>0.5$

- pleural fluid LDH/serum LDH $>0.6$

- pleural fluid LDH more than two-thirds of the upper limit of normal serum LDH

* If pleural fluid protein is $25-35 \mathrm{~g} / \mathrm{l}$ or serum protein level is abnormal, apply Light's criteria

$\mathrm{LDH}=$ lactate dehydrogenase; $\mathrm{TB}=$ tuberculosis.
Differentiation of transudate from exudate is key to further management. Treatment for transudative effusion relies on treatment of the underlying disease, and uncommonly requires specific pleural intervention. In contrast, exudative effusion usually needs further investigation and often requires intervention.

\section{Initial diagnostic approach}

The presence of bilateral, symmetrical effusions in the appropriate clinical context is highly suggestive of transudative effusion, and in general requires no further investigation. ${ }^{2}$ However, it should be noted that about $50 \%$ of heart failure

\section{Key Points}

Unilateral pleural effusion requires further aetiological investigation, with pleural fluid analysis as the usual first investigative step

All effusions in the context of pneumonic illness should be sampled to assess for the presence of complicated parapneumonic effusion $(\mathrm{pH}<7.2)$ or empyema (frank pus)

Ultrasound is a far more sensitive technique for the diagnosis of pleural effusion than chest radiography. In cases where initial 'blind' aspiration has failed, or in the presence of an anatomically complex collection, image guidance (ultrasound or computed tomography) should be sought

Drainage of undiagnosed pleural effusions 'to dryness' is not recommended, as this makes further investigation techniques more difficult. In the case of a breathless patient, removal of 1-1.5 litres of pleural fluid will usually alleviate symptoms

Pleural fluid cytology is positive in only $60 \%$ of malignant pleural effusions. A negative fluid cytology in the absence of another clear cause for pleural effusion should prompt further investigations via a respiratory specialist

KEY WORDS: empyema, investigation, malignant pleural effusion, pleural biopsy, pleural effusion 
effusions are unilateral and where bilateral may be larger on one side. ${ }^{3}$ In this circumstance or if the clinical course is atypical (eg lack of response to therapy), further investigations should be considered.

Unilateral effusions require further assessment. The initial investigation of choice is diagnostic pleural aspiration. Large effusions ( $>1 / 2$ hemithorax volume) may be aspirated easily without image guidance, but in the presence of a small effusion, or where initial 'blind' aspiration is unsuccessful, image guidance (usually ultrasound) should be sought. In the absence of a diagnosis (unless clearly infected), intercostal drain insertion and complete drainage of the chest is not recommended as this makes more difficult any further investigations that may be required. In symptomatic breathlessness with large effusions, large volume (eg 1 litre) thoracentesis for diagnostic/ therapeutic purposes is usually sufficient to control symptoms until initial investigation results are obtained. These patients can in general be investigated in the outpatient setting.

\section{Pleural fluid diagnostic tests}

\section{Appearance}

Frankly purulent pleural fluid is diagnostic of empyema; it may also be malodorous. Turbid pleural fluid may be seen in infected pleural effusion or in oesophageal perforation. 'Milky' pleural fluid should prompt consideration of empyema or a lipid abnormality.

\section{Biochemical parameters}

Fluid should be sent in all cases for measurement of:

- protein level

- lactate dehydrogenase (LDH), and

- glucose.

These parameters allow reliable differentiation of exudate from transudate by applying Light's criteria ${ }^{4}$ (for which simultaneous sampling of venous blood for protein and $\mathrm{LDH}$ is required) (Table 1). Pleural fluid $\mathrm{pH}$ measurement is recommended in cases of suspected infected pleural effusion (see below).

\section{Special tests}

Guidelines recommend biochemical analysis of pleural fluid in all sampled effusions as above, with microbiology (including specific requests for staining and culture of acid-fast bacilli) and cytology where indicated. ${ }^{5}$ Certain more specific tests should be undertaken, dictated by clinical circumstances, for example:

- amylase in suspected oesophageal perforation or pancreatitisassociated effusion, or

- lipid profile in suspected chylothorax or pseudochylothorax.

Pleural fluid autoantibody level measurement (eg antinuclear antibodies, rheumatoid factor) are representative of serum levels and add little diagnostic value.

\section{Radiological investigations}

Most pleural effusions are detected on plain chest radiography, although lateral (and specifically lateral decubitus) radiographs increase sensitivity. About $200 \mathrm{ml}$ of pleural fluid must be present before any change is evident on the plain posteroanterior (PA) chest radiograph. ${ }^{6}$ The classical appearance of pleural effusion is easily recognised. However, loculated fluid may appear atypically and encysted fluid within the lung fissure may give the appearance of an intraparenchymal mass (Fig 1).

\section{Thoracic ultrasound}

Lateral decubitus chest radiography has largely been superseded by thoracic ultrasound, which is more widely available and

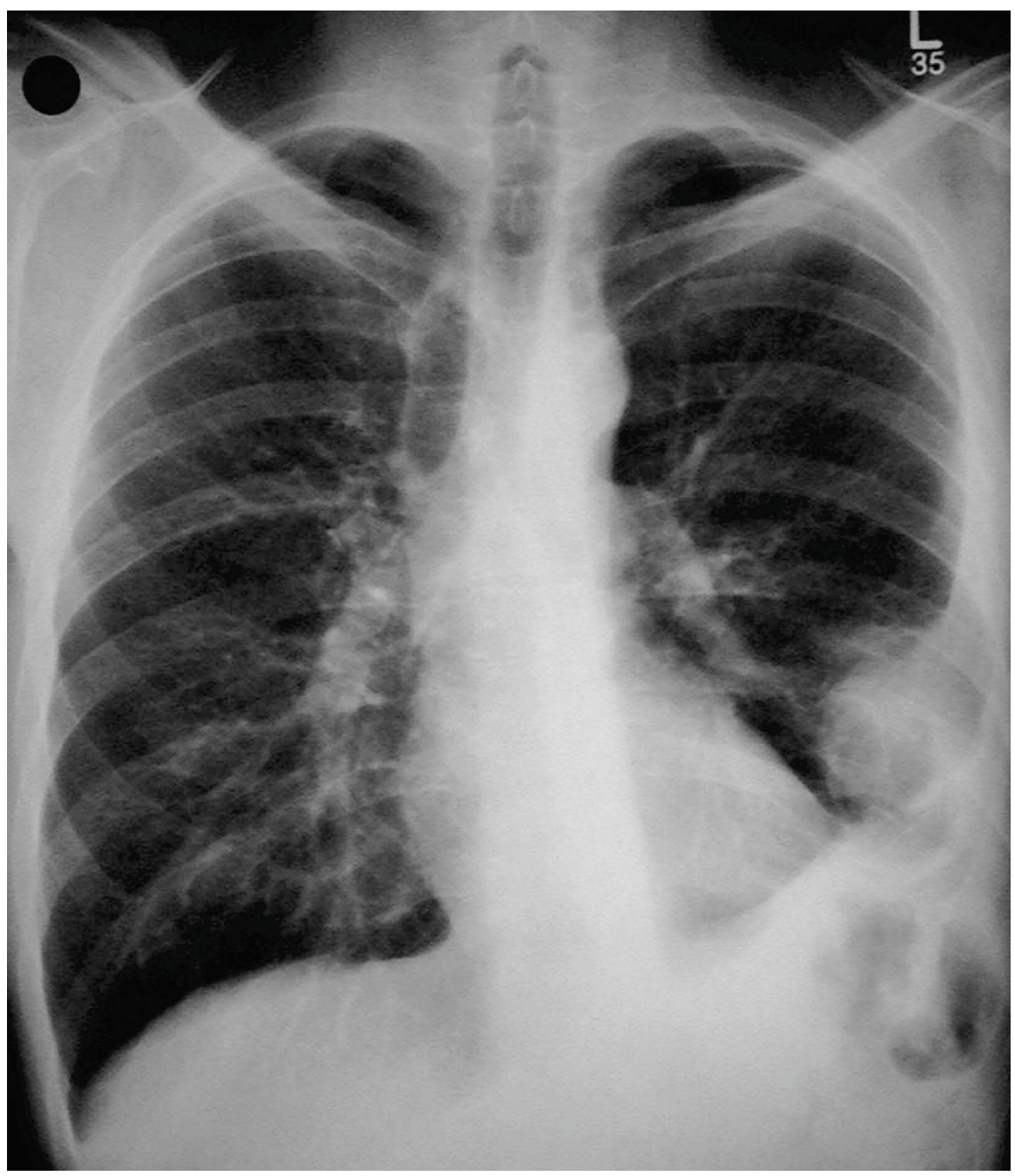

Fig 1. Encysted fluid in the fissure appearing as a lung mass. 
increasingly being performed by physicians on the ward. It permits detection of very small amounts of pleural fluid. Several studies have demonstrated that it is more sensitive in detecting fluid, more accurate in guiding aspiration and safer than 'blind' procedures (Fig 2). ${ }^{7}$ A recent National Patient Safety Audit committee report $^{8}$ detailing 12 deaths due to malposition of chest drains suggests that drains should be placed with ultrasound guidance wherever possible, always by an operator with adequate competence in both drain insertion technique and ultrasound.

\section{Contrast-enhanced computed tomography}

A powerful tool in the diagnosis of pleural effusion is contrast-enhanced computed tomography (CT). ${ }^{9}$ The technique is most valuable when:

- there remains a substantial effusion because it improves the contrast between pleural abnormality and fluid, and

- the scan is conducted in the late venous phase (ie 60-90 seconds after injection), permitting enhancement of the pleural surfaces.
CT permits assessment of the underlying lung parenchyma, mediastinal structures and associated liver and upper abdominal pathology. ${ }^{5}$

\section{Specific circumstances}

\section{Infective pleural effusion}

A pleural effusion occurs in about 50\% of cases of pneumonia. ${ }^{10}$ Most of them require no specific treatment, but it is mandatory to sample all but the smallest effusions as no clinical parameters are able to predict which patients will require more aggressive therapy. ${ }^{11}$ In cases of doubt, ultrasound or CT scanning should be requested to assess for possible effusion.

A suggested diagnostic algorithm for suspected infected pleural infection is shown in Fig $3 .{ }^{10} \mathrm{~A}$ combination of pleural fluid appearance, $\mathrm{pH}$ and microbiological analysis is required to assess the need for intercostal drainage. Frankly purulent fluid is diagnostic of empyema (pleural fluid $\mathrm{pH}$ is not required in this circumstance). In cases of non-purulent fluid in the context of an infective illness, accurate pleural fluid $\mathrm{pH}$ guides further management. Meta-analysis has demon-

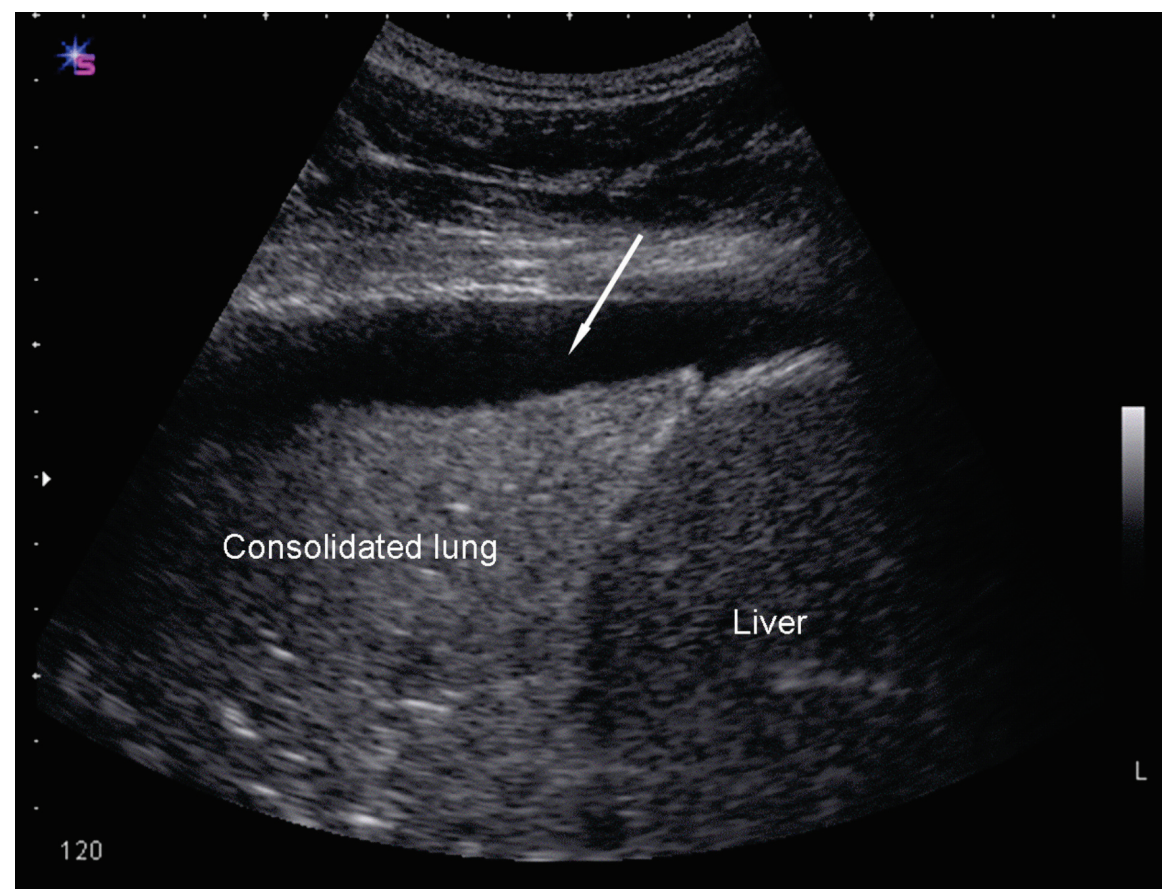

Fig 2. Thoracic ultrasound demonstrating consolidated lung and a very small parapneumonic effusion (arrow) about $1.5 \mathrm{~cm}$ deep. The chest radiograph showed basal consolidation only.

strated that acidic $\mathrm{pH}(<7.2)$ is associated with a 'complicated' clinical course and hence requires chest drainage. ${ }^{12}$ In contrast, non-acidic $\mathrm{pH}$ is associated with an uncomplicated course and therefore appropriate antibiotic treatment for the pneumonia alone is usually sufficient.

Although pH is a sensitive and specific marker of patients requiring intercostal drainage, decisions to initiate drainage must not be based solely on $\mathrm{pH}$. Repeat sampling should be considered in nonacidic effusion if there is clinical deterioration. It should also be noted that a number of conditions (which do not mandate prompt intercostal drainage) may result in a low pleural fluid $\mathrm{pH}$, including tuberculous pleural effusion, rheumatoid arthritis, oesophageal perforation and some malignant pleural effusions. $^{13}$

Recent data demonstrate that accurate pleural fluid $\mathrm{pH}$ measurement requires analysis by blood gas analyser (not litmus paper) within one hour of collection, with care taken to exclude all heparin, local anaesthetic and air from the sampling syringe. ${ }^{14}$ If pleural fluid is Gramor culture-positive, intercostal drainage is required regardless of pleural fluid appearance and $\mathrm{pH}$.

Even with frankly purulent fluid, microbiological analysis will be positive in only about $60 \%$ of cases. ${ }^{15}$ Therefore, a substantial number of patients will require empirical antibiotic regimens for the duration of treatment (Table 2). ${ }^{10}$

\section{Malignant pleural effusion}

Accurate diagnosis of tissue type is essential in further management of malignant pleural effusion. Although its presence (in non-mesothelioma) implies metastatic disease most commonly from lung, breast, bowel and lymphoma, ${ }^{16}$ the advent of more focused oncological therapies means that accurate diagnosis often alters management or provides prognostic information.

\section{Cytological analysis}

Pleural fluid should be sent for cytological analysis on diagnostic aspiration. A small amount $(10 \mathrm{ml})$ is sufficient in 
most circumstances, although local pathology preferences should be checked. Even with the use of modern immunostaining techniques, pleural fluid cytology has a diagnostic sensitivity of only $60 \%$ and a substantially lower sensitivity (ca 20\%) in mesothelioma. ${ }^{16}$ A second, separate pleural fluid aspirate increases diagnostic yield modestly (by ca $10 \%)$, but there is no further increase with a third sample. ${ }^{17}$ About $40 \%$ of cases of pleural malignancy will therefore remain undiagnosed after cytological sampling. Further tests are needed in this patient group.

\section{Contrast-enhanced computed tomography}

The next step is often contrast-enhanced CT which has a sensitivity of $90 \%$ for malignant pleural disease. ${ }^{9}$ Pleural tissue will be required for definitive diagnosis. The most widely available technique is 'blind' pleural biopsy (eg Abram's or Cope's needle) in which pleural tissue is obtained without image guidance. However, this technique provides only an additional 20\% diagnostic sensitivity and substantially less in mesothelioma.

\section{Pleural biopsy under image guidance}

Pleural biopsy performed under image guidance (in general CT) was superior to 'blind' pleural biopsy in a randomised trial. ${ }^{18}$ The diagnostic yield of CT-guided biopsy approaches 90\% in cytology negative cases. ${ }^{18}$ An alternative approach is local anaesthetic or 'physician-based' thoracoscopy in which endoscopes are entered into the pleural space under sedation and local anaesthesia. This procedure permits full drainage of the pleural space, pleural biopsy and, if required, therapy for recurrent effusion (talc poudrage pleurodesis) in the same sitting. There are no randomised trials of the diagnostic yield of thoracoscopy but large cohort studies suggest a sensitivity for malignancy in excess of $90 \%{ }^{19}$ CT-guided and thoracoscopic techniques are complementary, in that large effusions can be diagnosed and treated simultaneously using thoracoscopy,

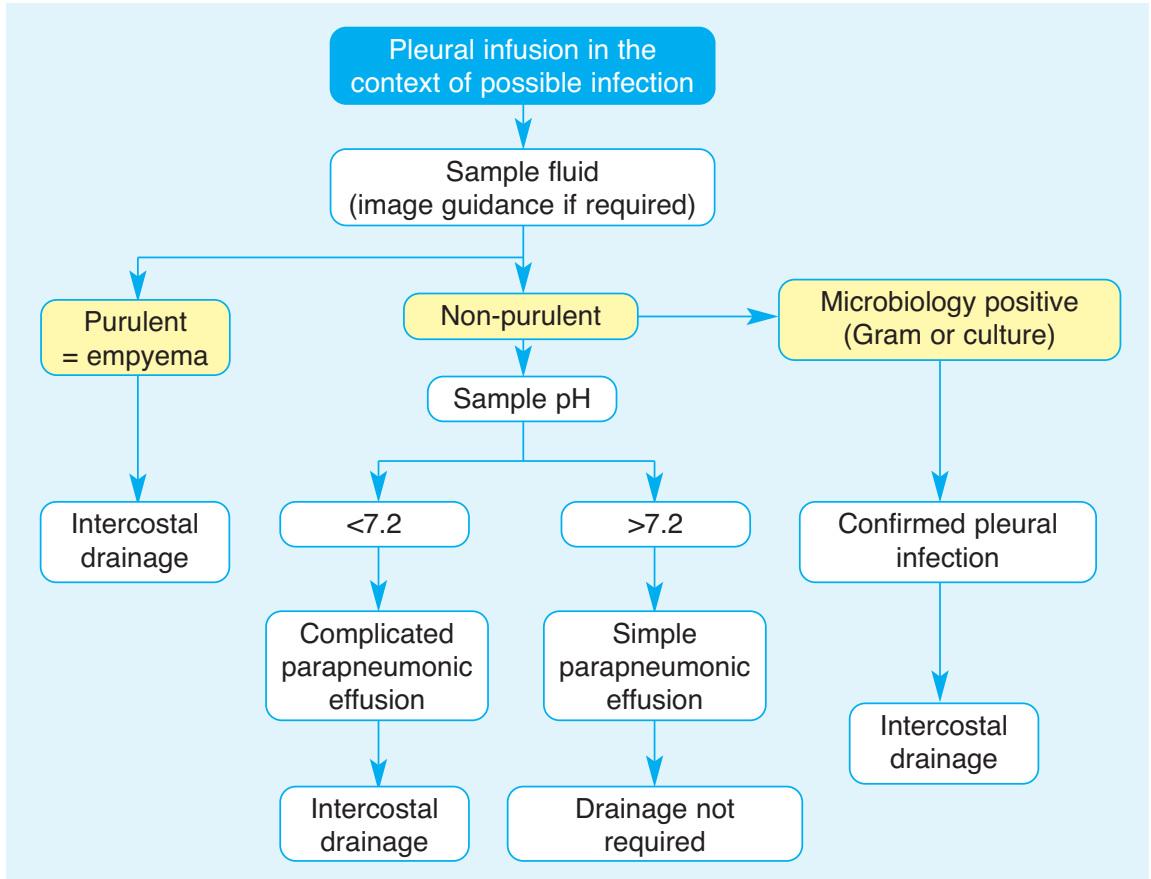

Fig 3. Investigation pathway for suspected infected pleural effusion.

Table 2. Causative organisms and suggested empirical antibiotic regimens for pleural infection.

Infection

\begin{tabular}{ll}
\hline Community acquired & Hospital acquired \\
\hline $\begin{array}{ll}\text { Causative organism (\% positive isolates)* } \\
\text { Streptococcus milleri group (32) }\end{array}$ & MRSA (28) \\
Anaerobic organisms (16) & Staphylococci (18) \\
Streptococcus pneumoniae (13) & Enterobacteriaceae (16) \\
Staphylococci (11) & Enterococci (13) \\
Other streptococci (7) & Anaerobic organisms (5) \\
Enterobacteriae (7) & Streptococcus milleri group (5) \\
Haemophilus influenza (3) & Pseudomonas spp (5) \\
Proteus spp (3) & Other streptococci (5) \\
Other (8) & Other (5) \\
Suggested empirical antibiotic regimen & \\
3rd generation cephalosporin or penicillin & Broad-spectrum cover to provide activity \\
with $\beta$-lactamase cover & against resistant Gram-negatives, MRSA \\
PLUS anaerobic cover (eg cefuroxime/ & and anaerobes (eg vancomycin PLUS \\
co-amoxiclav PLUS metronidazole) & meropenem) \\
\hline
\end{tabular}

* Microbiology from the largest UK microbiological cohort of patients with confirmed pleural infection. ${ }^{15}$ MRSA = methacillin-resistant Staphylococcus aureus.

whereas smaller effusions can be safely diagnosed using CT-guided biopsy.

\section{References}

1 Light RW. Diagnostic principles in pleural disease. Eur Respir J 1997;10:476-81.

2 Scheurich JW, Keuer SP, Graham DY.
Pleural effusion: comparison of clinical judgement and Light's criteria in determining the cause. South Med J 1989; 82:1487-91.

3 Light RW. Pleural diseases, 5th edn. Philadelphia: Lippincott, Williams \& Wilkins, 2007.

4 Light RW, Macgregor MI, Luchsinger PC, Ball WC Jr. Pleural effusions: the diagnostic 
separation of transudates and exudates. Ann Intern Med 1972;77:507-13.

5 Maskell NA, Butland RJ; Pleural Diseases Group, Standards of Care Committee, British Thoracic Society. BTS guidelines for the investigation of a unilateral pleural effusion in adults. Thorax 2003;58(Suppl 2): ii8-17.

6 Blackmore CC, Black WC, Dallas RV, Crow HC. Pleural fluid volume estimation: a chest radiograph prediction rule. Acad Radiol 1996;3:103-9.

7 Diacon $\mathrm{AH}$, Brutsche MH, Solér M. Accuracy of pleural puncture sites: a prospective comparison of clinical examination with ultrasound. Chest 2003; 123:436-41.

8 Risk of chest drain insertion. National Patient Safety Agency, UK 2009. Available at www.npsa.nhs.uk/nrls/alerts-anddirectives/rapidrr/risks-of-chest-draininsertion/

9 Leung AN, Müller NL, Miller RR. CT in differential diagnosis of diffuse pleural disease. AJR Am J Roentgenol 1990;154: 487-92.

10 Davies CW, Gleeson FV, Davies RJ; Pleural Diseases Group, Standards of Care
Committee, British Thoracic Society. BTS guidelines for the management of pleural infection. Thorax 2003;58(Suppl 2):ii18-28.

11 Davies CW, Kearney SE, Gleeson FV, Davies RJ. Predictors of outcome and longterm survival in patients with pleural infection. Am J Respir Crit Care Med 1999; 160(5 Pt 1):1682-7.

12 Heffner JE, Brown LK, Barbieri C, DeLeo JM. Pleural fluid chemical analysis in parapneumonic effusions. A meta-analysis. Am J Respir Crit Care Med 1995;151: 1700-8.

13 Heffner JE, Heffner JN, Brown LK. Multilevel and continuous pleural fluid $\mathrm{pH}$ likelihood ratios for evaluating malignant pleural effusions. Chest 2003;123:1887-94.

14 Rahman NM, Mishra EK, Davies HE, Davies RJ, Lee YC. Clinically important factors influencing the diagnostic measurement of pleural fluid $\mathrm{pH}$ and glucose. Am J Respir Crit Care Med 2008; 178:483-90.

15 Maskell NA, Batt S, Hedley EL et al. The bacteriology of pleural infection by genetic and standard methods and its mortality significance. Am J Respir Crit Care Med 2006;174:817-23.
16 Antunes G, Neville E, Duffy J, Ali N; Pleural Diseases Group, Standards of Care Committee, British Thoracic Society. BTS guidelines for the management of malignant pleural effusions. Thorax 2003; 58(Suppl 2):ii29-38.

17 Garcia LW, Ducatman BS, Wang HH. The value of multiple fluid specimens in the cytological diagnosis of malignancy. Mod Pathol 1994;7:665-8.

18 Maskell NA, Gleeson FV, Davies RJ. Standard pleural biopsy versus CT-guided cutting-needle biopsy for diagnosis of malignant disease in pleural effusions: a randomised controlled trial. Lancet 2003; 361:1326-30.

19 Harris RJ, Kavuru MS, Rice TW, Kirby TJ. The diagnostic and therapeutic utility of thoracoscopy. A review. Chest 1995;108: $828-41$. 